\title{
BNCC E SEMIÓTICA: UM DIÁLOGO MAIS QUE NECESSÁRIO
}

Ana Cristina dos Santos Malfacini (UERJ)

\begin{abstract}
"A leitura do mundo precede a leitura da palavra; daí que a posterior leitura desta não possa prescindir da contiunuidade da leitura daquele. Linguagem e realidade se prendem dinamicamente"

Paulo Freire
\end{abstract}

Resumo: Em um contexto de pandemia, de crise econômica, de expansão do uso da tecnologia na preparação e na condução de aulas remotas e de implementação de novos documentos oficiais de orientação pedagógica no Brasil (com a instituição de ajustes curriculares sugeridos pela Base Nacional Curricular Comum - BNCC), muitos professores, sobretudo da área de Linguagens, sentiram-se perdidos. A proposta desse artigo é trazer à baila as reais diretrizes dos documentos oficiais, ressaltando como os gêneros (BAKHTIN, 1992[2003]) podem e devem ser usados como fonte fundamental das aulas de língua materna. Ainda que tantos outros trabalhos já tenham discutido essa orientação, chamamos atenção para um alerta importante: a questão não é eleger uma nomenclatura terminológica sobre gêneros para serem "decoradas" pelos educandos, mas sim elaborar uma análise multissemiótica (SIMÕES, 2009; ROJO; MOURA, 2012) de qualidade com os leitores em formação, sobretudo com o amparo da Teoria da Iconicidade Verbal - TIV (SIMÕES, 2009). Paradoxalmente, é recorrente a queixa que ouvimos de muitos professores em formação, reclamando que sabem muito pouco ou até que nunca estudaram Semiótica. Este trabalho, então, propõe-se, ainda uma vez, tentar sinalizar esse contrassenso. Afinal, como pode a BNCC propagar a necessidade de uma análise linguístico-semiótica dos textos, se boa parte dos professores sequer sabe como fazê-lo?

Palavras-chave: BNCC. Semiótica. Multissemiose. TIV. Gêneros na escola.

Abstract: In a pandemic context, with economic crisis and an expansion of the usage of technology when preparing and teaching remote classes, and the implementation of new official documents of pedagogical guidance in Brazil (with the establishment of curricular adjustments 
suggested by Base Nacional Comum Curricular - BNCC), many teachers, mainly in Languages area, have felt lost. The aim of this article is to bring up the real directions of the official documents, highlighting how the genres (BAKHTIN, 1992[2003]) can and must be used as main reference in mother language classes. Even if a lot of other studies have already discussed these instructions, we stand out for an important alert: the question is not to elect a terminological nomenclature to be memorized by students, but to build a multisemiotics analisis (SIMÕES, 2019; ROJO; MOURA, 2012) of quality with training readers, especially with Teoria da Iconicidade Verbal's support - TIV (SIMÕES, 2009). Paradoxically, it is recurrent the complaint we listen from many training teachers, complaining that they know too little or that they have never studied Semiotics. This study, then, once still, tries to sinalize this contradiction. After all, how can BNCC spread the need of a linguistic-semiotic analisis of a text, if a great number of the teachers don't know how to do it?

Keywords: BNCC. Semiotics. Multissemiosis. Genders at school.

\section{INTRODUÇÃO}

Muito se comenta a respeito do papel do professor na contemporaneidade. A despeito da ascensão da tecnologia como recurso didático e da crise econômica que tem assolado essa classe, nada substitui o importante papel que esse profissional representa para uma cultura letrada que vise ao pensamento crítico e autônomo, e cuja orientação retoma o melhor de Paulo Freire em sua Pedagogia da Autonomia (1996). O pensar autônomo, o despertar da curiosidade e o criticar das formas tradicionais de atuação nunca estiveram tão atuais, sobretudo com a pandemia da COVID-19, a qual nos fez refletir sobre uma série de paradigmas educacionais, vigentes nas escolas até 2020. 
No que tange especificamente às aulas de Língua Portuguesa, tem-se visto um movimento no qual professores vêm procurando, em textos, subsídios para as discussões linguísticas na escola. É fato que os Parâmetros Curriculares Nacionais (BRASIL, 1998) já preconizavam a abordagem em sala de aula daquilo que hoje chamamos de teoria dos gêneros (BAKHTIN, 1992[2003]), numa tentativa de trazer à escola uma abordagem enunciativo-discursiva dos fenômenos que preenchem os currículos da aula de língua materna. Lembremos que os gêneros textuais são textos materializados em situações de comunicação recorrentes encontradas em nosso cotidiano, os quais apresentam padrões sociocomunicativos característicos, definidos por composições funcionais, objetivos enunciativos, estilos realizados na integração de forças históricas, sociais, institucionais, técnicas etc. São incontáveis e podem expressar-se sob designações diversas, constituindo-se sob formas textuais escritas ou orais bastante estáveis, histórica e socialmente situadas (MARCUSCHI, 2002, p. 155).

A instituição da nova Base Nacional Curricular Comum (doravante BNCC), documento aprovado pelo governo em 2017 e cuja implementação escolar se dará como exigência a partir de 2021, só ratifica o papel dessa abordagem, na 
medida em que determina quais competências, habilidades e conteúdos são essenciais a cada aluno da educação básica, em cada etapa de escolaridade, independente de onde os jovens morem ou estudem. Por exemplo, vale lembrar que, embora o Ensino Médio possa adotar $40 \%$ de sua grade de horários com os itinerários formativos (escolha de qual área do conhecimento desejam se aprofundar, sendo a de Linguagens e suas Tecnologias uma das opções), os componentes de Língua Portuguesa deverão estar presentes nos três anos de escolaridade, desenvolvendo como foco o protagonismo do educando em sociedade, bem como sua autonomia e seu desenvolvimento para o mundo do trabalho.

Cumpre ainda dizer que, na BNCC, a organização das práticas de linguagem é feita em quatro eixos: leitura de textos, produção de textos, oralidade e análise linguística/semiótica, os quais demonstram a importância da contextualização do conhecimento escolar e, simultaneamente, devem mostrar-se em situações significativas para os estudantes. Assim, são cinco os campos de atuação considerados na área de Linguagens: Campo da vida cotidiana (nomenclatura somente usada nos anos iniciais, com bilhetes, receitas, convites, por exemplo, numa demonstração de que a criança já domina a leitura e 
escrita desses gêneros desde a infância); Campo artísticoliterário (no qual serão trabalhadas obras de arte, poemas, coreografias, fotografias etc., bem como seu processo de produção); Campo das práticas de estudo e pesquisa (em que gráficos, infográficos, tabelas, entre outros, serão abordados em diálogo com outras áreas do conhecimento, como as ciências exatas e humanas); Campo jornalísticomidiático (no qual os gêneros jornalísticos, como notícias, charges, crônicas, editoriais, artigos de opinião serão vistos e, também, os "novos gêneros", como canais do Youtube, do TIK TOK, cujos vídeos atraem fortemente um público mais jovem - aliás, vale ressaltar que esta é uma novidade na abordagem da BNCC, já que estimula claramente o trabalho com esses textos em aula, mostrando de maneira objetiva que a escola já pode e deve prescindir de produções textuais que transcendam o uso do papel) e Campo de atuação na vida pública (em que documentos oficiais, como o Estatuto da Criança e do Adolescente e a Constituição Federal, de 1988, por exemplo, deverão ser trabalhados na escola, com o intuito de que os educandos desenvolvam sua cidadania).

No caso desses dois últimos, jornalístico-midiático e da vida pública, cumpre salientar que estes aparecem fundidos já nos anos iniciais do Ensino Fundamental, com 
a denominação Campo da vida pública. Essa orientação demonstra nitidamente que o trabalho com os gêneros deverá ser contínuo, sobretudo se levarmos em conta que a BNCC reduz em um ano escolar as metas de alfabetização, determinando que os alunos já consigam ler de forma satisfatória um pequeno texto ao fim do 20 ano do Ensino Fundamental, para, a partir do 3o ano, já poderem ser conduzidos por um trabalho no qual os gêneros ancorem a aprendizagem das linguagens múltiplas em que as crianças estão submersas fora da escola.

Reforçamos: um trabalho contínuo, contextualizado, a partir dos gêneros parece-nos uma realidade da qual a escola não tem como fugir, até porque vai ao encontro das necessidades educacionais exigidas pelo terceiro milênio. No entanto, isso não significa que os alunos deverão substituir listas de substantivos, adjetivos, verbos etc. por características dos gêneros e tipificidades a decorar. É nesse sentido que nossa fala se mantém há mais de uma década de pesquisas: cabe ao professorado ter esse olhar, com a sensibilidade de usar as aulas de língua materna como uma oportunidade de despertar nos educandos olhares para múltiplos fenômenos linguístico-semióticos. E quanto à Semiótica, retomaremos esse tópico em alguns parágrafos. 


\section{Conforme trecho da BNCC:}

As práticas de linguagem contemporâneas não só envolvem novos gêneros e textos cada vez mais multissemióticos e multimidiáticos, como também novas formas de produzir, de configurar, de disponibilizar, de replicar e de interagir. As novas ferramentas de edição de textos, áudios, fotos, vídeos tornam acessíveis a qualquer um a produção e disponibilização de textos multissemióticos nas redes sociais e outros ambientes da Web. Não só é possível acessar conteúdos variados em diferentes mídias, como também produzir e publicar fotos, vídeos diversos, podcasts, infográficos, enciclopédias colaborativas, revistas e livros digitais etc. Depois de ler um livro de literatura ou assistir a um filme, pode-se postar comentários em redes sociais específicas, seguir diretores, autores, escritores, acompanhar de perto seu trabalho; podemos produzir playlists, vlogs, vídeos-minuto, escrever fanfics, produzir e-zines, nos tornar um booktuber, dentre outras muitas possibilidades. (BRASIL, 2018, p. 68)

Se olharmos pelo prisma de documentos oficiais como a Lei de Diretrizes e Bases (LDB), de 1996, e até mesmo dos Parâmetros Curriculares Nacionais (PCNs), de 1998, veremos na BNCC um diálogo e uma atualização, na medida em que as pesquisas linguísticas recentes e as transformações das práticas de linguagem fomentadas pelo desenvolvimento 
e aprimoramento das tecnologias digitais de informação (TDIC) exigiram uma dinamização do trabalho com o texto em sala. Assim, a perspectiva enunciativo-discursiva da linguagem, na qual "a linguagem é uma forma de ação interindividual orientada para uma finalidade específica; um processo de interlocução que se realiza nas práticas sociais existentes numa sociedade, nos distintos momentos de sua história" (BRASIL, 1998, p. 20), é mantida, assumindo o texto como "fruto de um processo extremamente complexo de linguagem e construção social, de construção social de sujeitos, de conhecimentos de natureza diversa" ( $\mathrm{KOCH}$; ELIAS, 2018, p. 18). Então, visto o texto como um fenômeno multifacetado, a proposta da BNCC assume a sua centralidade na fundamentação do trabalho em aula, relacionando-o a seus contextos de produção e a habilidades quanto ao uso significativo da linguagem em atividades de leitura, escuta e produção textual em mídias e semioses diversas (BRASIL, 2018, p. 67).

A grande questão é que, a nosso ver, é mister debater a negligência da Semiótica nos currículos dos cursos de formação de professores pelo país afora. Ver um documento da relevância da BNCC falar sobre semiose e multissemioses e não ver, em boa parte dos cursos de 
graduação, espaço para a discussão dos multiletramentos e de textos multissemióticos é, no mínimo, controverso. Afinal, é papel das universidades oferecer esse cabedal teórico ao professor, principalmente de uma área tão transdisciplinar como a de Linguagens, dando a ele condições necessárias para cumprir sua tarefa de ser o multiprofessor que a escola e a sociedade cobram dos profissionais do ensino no século XXI.

Foi esse debate que nos motivou à publicação deste trabalho: ainda que já tenhamos publicado outros artigos nos quais a defesa da Semiótica fosse nosso objetivo maior (MALFACINI; SIMÕES, 2010; MALFACINI, 2016), pouco se notou de avanço na base formadora dos professores no sentido de entender melhor seus conceitos e aplicá-los em aula. Especificamente com as necessidades que a pandemia nos impôs na preparação de trabalhos on-line, vimos como os docentes se mostraram perdidos e confusos diante do domínio das novas tecnologias. Não seria diferente se toda uma teoria sígnica lhes pudesse abrir os horizontes de análise? Mais uma vez, então, recorremos a Simões, que vem incansavelmente levantando esse debate acadêmico há mais de duas décadas em suas publicações.

A estanqueidade e o monologismo não cabem mais nos espaços interativos [nesse 
início de século]. Tudo se comunica com tudo e se projeta em tudo. Tudo atravessa tudo. No entanto, a organização da leitura (ou interpretação) dessa cultura caleidoscópica carece de uma instrumentalização técnica cada vez mais apurada. Em função disso, a ciência semiótica traz consigo a imposição de um domínio plural de conhecimentos, uma vez que o universo semiótico, e o homem interage com os sinais, lendo os que $o$ antecedem e formulando novos sinais em suprimento das necessidades emergentes. Com esse suporte teórico, é possível verificarem-se as intersecções entre as diversas áreas do saber humano e capacitar o aluno para que saiba analisar as especificidades de cada manifestação, sem perder a visão do todo em que elas estão inseridas, e percebendo que as particularidades têm um sentido socialmente construído. (2001, p. 114)

Para a pesquisadora, graças a uma efervescência sociocultural - com a pintura, a fotografia e, por último, o cinema -, ocorreu uma mudança no ensino, principalmente na área de linguagens, por meio da constituição de signos observáveis no cenário cinematográfico, televisivo e de imagens fixas da fotografia e da pintura. Por isso, o texto deixa de ser meramente verbal e apresenta um espaço multissígnico e multimídia (SIMÕES, 2009, p. 53).

A propósito dessa efervescência a que aludimos acima, o Grupo de Nova Londres (GNL), um grupo de pesquisadores 
reunido em 1996, em Connecticut, nos Estados Unidos, propôs, após dias de discussões, um manifesto no qual propunha que a escola tomasse sua responsabilidade no letramento dos gêneros emergentes da sociedade, com vistas a contemplar não só as tecnologias de informação, como também a variedade cultural já presente no ambiente escolar, mas muitas vezes marginalizada pela intolerância na convivência com as minorias e com a alteridade. Foi a partir de então que se cunhou o termo multiletramentos (não confundir com letramentos múltiplos), palavra na qual o morfema "multi" se propõe abarcar as novas ferramentas de acesso à comunicação, que trazem aos textos um caráter multimodal, hipersemiótico - ou hipermidiático, como a literatura especializada tem preferido usar hoje (ROJO; MOURA, 2012, p. 12-13).

Assim, fica fácil concluir que a multimodalidade ou multissemiose dos novos gêneros de circulação social apontam cada vez mais para a necessidade de multiletramentos, à medida que as diversas linguagens (ou também chamados modos ou semioses) precisam ser fundamentalmente compreendidas para se tornarem significativas. Com isso, não basta educar o homem para atuar isoladamente, visto que a nova organização social implica a estimulação de todos os 
sentidos e inteligências na interação com o todo a sua volta; é preciso incrementar a leitura multitemática, sobretudo, explorando a internet como fonte a partir da qual se devem promover leituras mais aprofundadas (SIMÕES, 2009, p. 55).

Diante desse contexto, propomo-nos aplicar conceitos semióticos à leitura e interpretação de gêneros diversos, no intuito de demonstrar (ainda uma vez) como a epistemologia semiótica pode ser plenamente aplicável ao nosso trabalho didático-pedagógico, a fim de enriquecê-lo exatamente nos preceitos que os documentos oficiais vêm defendendo há décadas. Dito isso, destituindo-nos do medo de parecermos repetitivos nesse propósito, após uma breve retomada dos conceitos principais que adentram o tema, aplicaremos os conceitos basilares de Peirce, Nöth, Santaella, Simões, entre outros autores, em textos diversos (verbais, não verbais, mistos), até com o intuito de empoderar professores a tornarem suas aulas mais profícuas, dinâmicas, interativas, ainda que sejam obrigados, em algumas instituições, a usarem materiais didáticos já previamente escolhidos, como liros didáticos ou apostilas de sistemas de ensino multinacionais.

\section{SEMIÓTICA - UM SABER SEMPRE ATUAL}

Podemos definir de maneira simplória a Semiótica como uma doutrina formal dos signos. É a ciência dos signos e do 
processo significativo (semiose) na natureza e na cultura (NÖTH, 1995, p. 17), tendo como objeto de investigação todas as linguagens possíveis - artes visuais, músicas, fotografia, cinema, culinária, vestuário, gestos, religião, ciência etc. Semiótica - do grego semeion - é o estudo dos signos, que, por sua vez, são a representação de uma determinada coisa - a qual não está lá (SANTAELLA, 2006, p. 17).

A Semiótica é um saber muito antigo que adquiriu novos contornos, sobretudo com os estudos de Charles Sanders Peirce (1839-1914), pai da Semiótica, e Ferdinand de Saussure (1857-1913), precursor da Semiologia. Na visão de Saussure, o signo pode ser definido por suas partes constituintes - significante/significado - em uma relação arbitrária. Como uma folha de papel sulfite, os signos teriam duas faces: a primeira, a do significante, seria a base para a expressão de uma ideia. A face do significado é a própria ideia ou o conteúdo intelectual apresentado, ao qual se refere o significante. Portanto, o signo, para Saussure, é um elemento dicotômico. Com isso, não se pode admitir a existência do significante sem o significado e vice-versa, assim como não é possível estabelecer ou definir um elemento de relação objetiva entre o conceito e sua imagem acústica. 
Já Peirce, como criador de uma semiótica de base lógicofilosófica (também chamada semiótica de base americana), teve a pretensão de fundar um estudo que pudesse ser aplicado a qualquer interpretação sígnica, o que conseguiu a partir das tríades fundadas por ele. Sendo assim, partiu do conceito de signo, desdobrando-o sob o ponto de vista do objeto (qualissigno, sinssigno, legissigno), do próprio signo (ícone, índice, símbolo) e do interpretante (rema, dicente, argumento).

$\mathrm{Na}$ linha semiótica do cientista americano, um signo, ou representâmen, é aquilo que, sob certo aspecto ou modo, representa algo para alguém (PEIRCE, 2000, p. 46). O representâmen é o signo primeiro, é o signo como tal; o objeto é a representação do signo e, finalmente, o interpretante é a consciência intérprete do signo. Todo signo gera uma semiose, ou seja, um outro signo fruto da mente que, por assim dizer, remete a outro signo. Esse processo é o que autor chama de interpretante.

Cumpre salientar que Peirce divide o estudo dos signos em ramos diferentes para fins de análise: a primeira tricotomia trata do signo em si mesmo, a segunda refere-se às relações que o signo tem com o seu objeto e a terceira apresenta as relações entre o signo e o seu interpretante. Para fins de aplicação didática, deter-nos-emos à segunda tricotomia, na qual nos debruçaremos no presente estudo. 
Na sua segunda tricotomia, Peirce (2000, p. 52) apresenta o signo, que pode ser denominado como ícone, índice ou símbolo.

O ícone é um signo que se refere ao objeto, o qual é representado apenas em virtude de seus caracteres próprios (caracteres que ele igualmente possui quer um tal objeto realmente exista ou não). A palavra ícone vem do grego e quer dizer imagem, por isso, quando representamos algo por meio de um desenho, estamos utilizando um ícone, por exemplo. Quanto mais semelhante a imagem for de seu objeto, mais icônica será (MALFACINI, 2012, p. 897).

O índice é um signo que se refere ao objeto que denota em virtude de ser realmente afetado por esse objeto, sendo, portanto, um signo de referência a um dado objeto e/ou objetivo. O índice, assim, apresenta uma relação direta com o objeto, conferindo-Ihe um traço de proximidade. São signos indiciais as nuvens negras, como sinal de que irá chover, por exemplo, ou as pegadas na areia como evidência de uma presença recente naquele lugar. "Onde há fumaça, há fogo", ditado popular, é uma excelente representação indicial. Em suma, esse tipo de signo funciona como um sinal da ocorrência de algo.

Já o símbolo é um signo que se refere ao objeto que denota em virtude de uma lei, normalmente uma associação de ideias 
gerais que opera no sentido de o fazer com que seja interpretado como se referindo àquele objeto (MALFACINI, 2012, p. 898). Muitas vezes, o objeto não parece com sua representação, sendo a associação do signo ao objeto geralmente instituída ao longo do tempo, por meio de uma assimilação cultural. Um exemplo interessante é o do "ícone" do comando salvar documento, no Microsoft Word. A partir do momento em que as novas gerações não conhecem mais a imagem de um disquete, antigo artefato usado para salvamento de documentos em computadores mais antigos, a semelhança com o objeto se perdeu. Assim, a associação hoje se faz de maneira simbólica, já que se tornou assimilativa e até arbitrária, por já fazer parte de uma convenção social de uso coletivo.

Eis uma aplicação desses conceitos, a fim de melhor esclarecê-los.

Figuras 1 e 2 - $O$ gênero charge em retomada intertextual da obra de Magritte

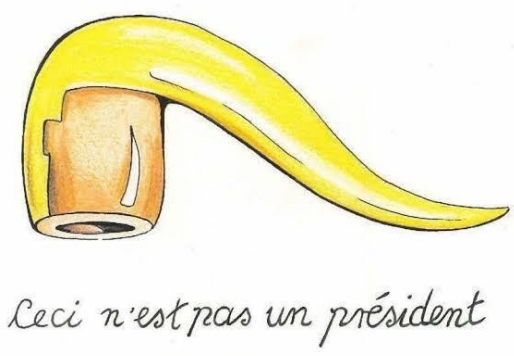




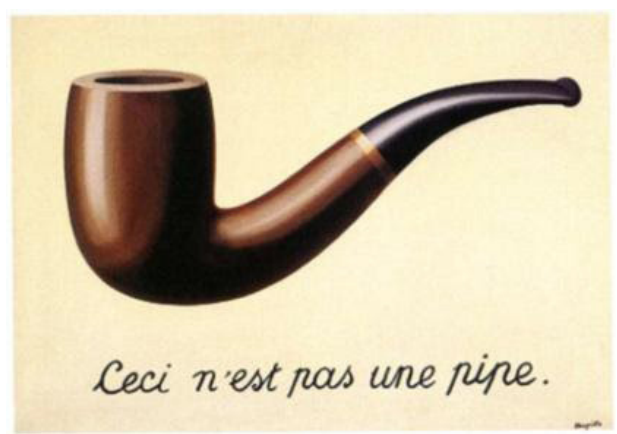

Fonte: Figura 1 - https://politicalcharge.org/2020/11/07/the-weeks-best-cartoons-election2020-edition $/{ }^{1}$ - Figura 2 - https://arteeartistas.com.br/a-traicao-das-imagens-de-renemagritte ${ }^{2}$

No exemplo à direita, temos uma reinterpretação da obra clássica do surrealista belga René Magritte (18981967). A pintura do artista A traição das imagens (19281929) mostra-se como uma provocação à nossa noção de sentido das coisas. Magritte nega aquilo que vemos ao grifar sob o desenho a frase "Ceci n'est pas une pipe" ("Isso não é um cachimbo"), desafiando-nos a repensar convenções artísticas e sociais. Ao intencionar desfazer a ligação entre a imagem (ícone) e a palavra (ícone gráfico), o artista esvazia de sentido aquilo que convencionamos entender como "cachimbo", inclusive propondo com isso uma reflexão sobre o papel da arte na sociedade - repare que isso não é um cachimbo, mas a representação artística de um cachimbo. Assim, pintura torna-se um ícone, pois

\footnotetext{
1 Acesso em 20 jan. 2021.

2 Acesso em 20 jan. 2021.
} 
traz características daquilo que conhecemos como o objeto cachimbo e, portanto, estimula a consciência que, por sua vez, a associa a um objeto significado. A esse processo interpretativo chamamos de interpretante.

Na charge à esquerda, a crítica social se apropriou da crítica de Magritte usando indícios que trazem à mente a imagem de uma pessoa em específico (o ex-presidente norte-americano Donald Trump), numa visível sátira a seu topete exótico. Independente de o espectador conhecer ou entender a posição política defendida pela charge - ou mesmo ela-, a mensagem se torna clara. Se a frase da charge mantivesse a mesma legenda ("isso não é um presidente"), mas o signo do cachimbo fosse o cachimbo original (não se alterando posição e cores), a crítica não existiria e estaria desfeita a originalidade intertextual da obra. Também percebemos que o signo aqui tem mais profundidade de sentido, ao aludir a uma política que desgoverna um país, ainda mais depois da decisão de não querer entregar a cadeira presidencial. A crítica, então, se dá ao afirmar que a pessoa que está de algum modo retratada não corresponde à ideia que temos de um presidente como deve ser. Aliás, como um símbolo se constrói a partir de convenções sociais, não parece demais vaticinar que, em algum tempo, 
o ex-presidente norte-americano esteja associado à noção de fracasso político, petulância, violência, ignorância, entretantos episódios nos quais esteve envolvido durante sua estada na Casa Branca.

\section{A TEORIA DA ICONICIDADE VERBAL (TIV) PROPOSTA POR DARCILIA SIMÕES}

Na esteira ainda da semiótica peirceana, voltando-a ao objetivo de compreender as relações sígnicas e amparar o trabalho com o texto escrito, destacamos o livro Iconicidade Verbal: teoria e prática (2009), de Darcilia Simões, que estuda as contribuições da percepção dos signos na distinção da relação dos processos cognitivos com a estrutura dos textos verbais. Na obra, a autora esclarece que existem níveis ou tipos de iconicidades para avaliar uma produção textual. Vale ressaltar que entendemos iconicidade aqui como

uma qualidade de natureza plásticoimagética que pode orientar o leitor para uma tomada do texto como um desenho constituído por um traçado completo em que podem misturar-se às letras das palavras e enunciados, formas, cores, posições, figuras etc.; do diálogo entre essa variedade de signos resulta a compreensão da mensagem (SIMÕES, 2009, p. 101)

Assim, pode-se determinar vários níveis em que se pode buscar a iconicidade de um texto, a saber: 1 - diagramática; 
2 - lexical; 3 - isotópica; 4 - alta ou baixa iconicidade; 5 eleição de signos orientadores ou desorientadores (SIMÕES, 2009 , p. 80). Com esse construto, a autora prova que a teoria da iconicidade verbal - doravante TIV - atua como uma solução consistente para preencher algumas lacunas vividas pelos professores em suas atividades didáticas. Com um aporte científico, embasado na teoria semiótica de Peirce, o trabalho docente pode abandonar achismos comuns no ensino do texto, ancorando-se em uma análise séria e criteriosa de fatos da língua. Explicaremos melhor a terminologia nos parágrafos a seguir.

Entende-se por iconicidade diagramática o projeto visual ou sonoro e a estruturação dos sintagmas do texto, conforme o raciocínio utilizado por quem produz o texto. Essa iconicidade consiste basicamente na análise da diagramação do texto, com vistas a relacionar aspectos como a configuração de versos e até parágrafos e sua contribuição para a compreensão textual. Dentro deste tópico de análise, avalia-se o alinhamento de manchetes, do título e dos subtítulos de obras literárias, entre outros exemplos. 
Figuras 3 e 4 - 0 gênero bilhete e suas acepções nas redes sociais
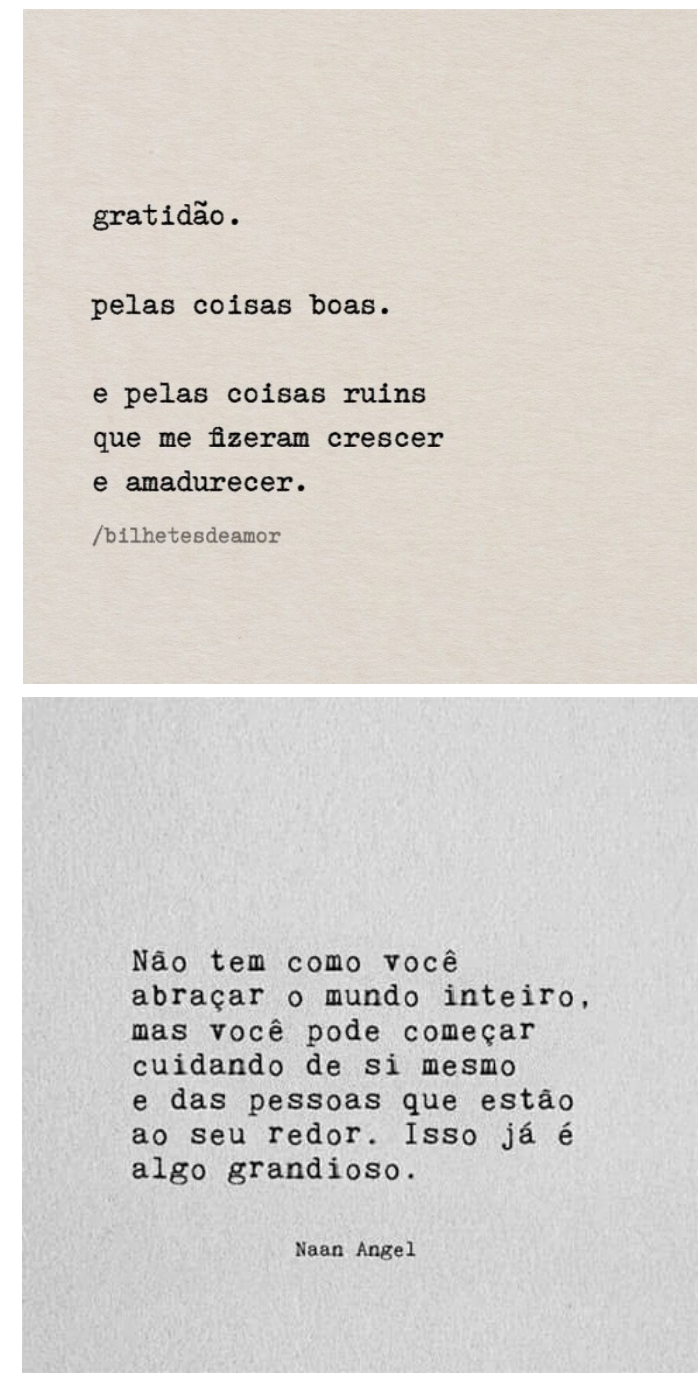

Fonte: Facebook - https://www.facebook.com/maisbrasil/photos/a.643250572352892/205246 $5601431375 /{ }^{3}$

3 Acesso em 15 jan. 2021. 
Nos excertos acima, vemos dois exemplos da página do Facebook "Mais Brasil", na qual são postados bilhetes e outras pequenas mensagens motivacionais, religiosas, amorosas etc. Estes são excelentes exemplos de um hibridismo intergêneros - ou intertextualidade intergêneros -, visto que, mesmo sendo tipificados como bilhetes, tanto não seguem um layout padrão (por não contarem com datas, interlocutores definidos ou assinaturas), como ainda apontam para um certo lirismo, como pequenos textos motivacionais que imitam a disposição gráfica de poemas (reparem que a análise como poemas talvez remeta ao espaço diagramado no "papel", o que também é assunto para discussões em aula). Conforme Marcuschi, "gêneros não são entidades naturais como borboletas [...]. Uma publicidade pode ter o formato de um poema ou de uma lista de produtos em oferta; o que conta é que divulgue os produtos e estimule a compra por parte dos clientes daquele produto" (2002, p. 30).

Assim, é notório como a formação semiótica deve estar consolidada na formação do professor da aéra de Linguagens, afinal cabe aos mestres suscitarem nos alunos discussões para que percebam, por exemplo, que, por fazerem parte de uma rede social, tais bilhetes precisam 
ser atemporais, podendo, inclusive, ser direcionados a vários possíveis leitores. Tratar de uma intergenericidade entre os textos é, em última análise, alertar os alunos de que a hibridização é um aspecto comum na história dos textos, já que os gêneros se prestam a necessidades sociais e coletivas de uma época. Sendo assim, numa era em que mensagens de WhatsApp são tão comuns à vida das famílias, é uma excelente oportunidade de tratar da historicidade e da evolução dos gêneros, ressaltando como a função cultural e a histórica estão intrinsecamente ligadas às suas construções sociais.

Descrita por Simões como "potencial de ativação de imagens mentais" (2009, p. 86), a iconicidade lexical consiste em analisar os itens lexicais/vocabulares usados no texto, em uma ativação que represente ícones e índices ao leitor. Quanto maior conhecimento da língua o autor tiver, mais fácil será a apreensão de signos para os interlocutores. 
Figura 5 - Análise multissemiótica de capa de jornal

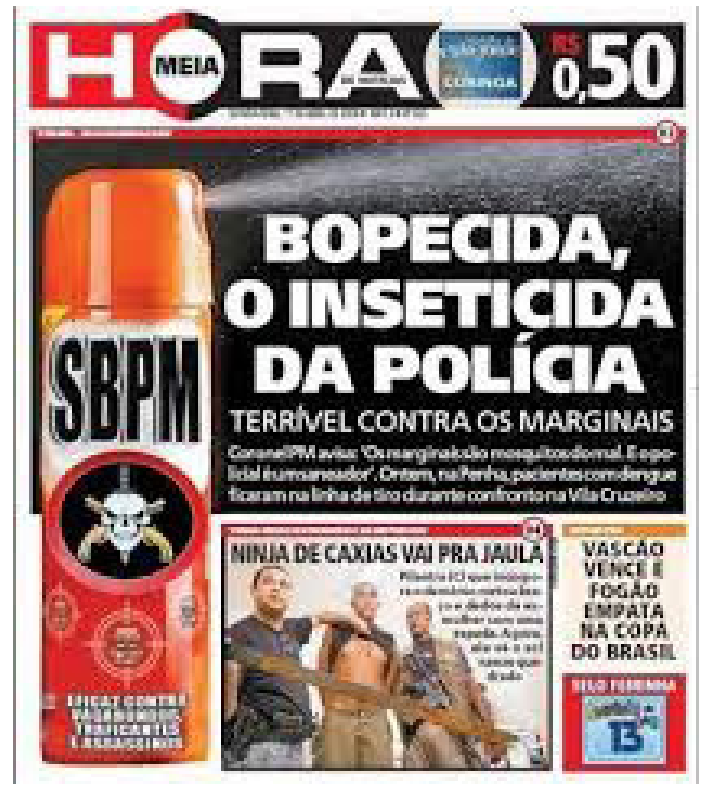

Fonte: Jornal Meia Hora de 17 abril de 2008.

No exemplo do jornal carioca Meia hora, há um neologismo com a sigla BOPE (Batalhão de Operações Especiais), batalhão policial que se tornou muito familiar ao brasileiro, sobretudo depois do famoso filme Tropa de Elite. No termo bopecida, ao nome da corporação carioca agregase um radical latino ("-cida"), que significa extermínio ou agente que provoca morte. Com isso, entende-se claramente o potencial icônico da palavra bopecida como a de um exterminador de bandidos (no lugar de mosquitos) , como sugeriria a presença de uma famosa marca de 
inseticida em aerosol vendida nos principais mercados. Além disso, é interessante notar a semelhança fonética entre o nome da marca, SBP, e um outro neologismo em SBPM, em alusão direta à sigla PM, usada popularmente para referirmo-nos à Polícia Militar.

Uma outra questão interessante a ser trabalhada com os alunos em um nível multissemiótico seria: se inseticida é aquele que mata o inseto, homicida é aquele que mata o homem, suicida é aquele que se mata, bopecida seria aquele que mata o Bope? Essa discussão poderia ser instigantemente conduzida, uma vez que a iconicidade dos elementos gráficos usados na capa não autorizariam tal interpretação. Assim, embora o processo de formação da palavra bopecida seja reconhecido no padrão morfológico do Português, este não corresponderia, ao pé da letra, ao que a manchete quis sugerir. Todo esse levantamento só ratifica a relevância do estudo da lexicalidade icônico-indicial, como Simões bem nos alertou em sua TIV, sobretudo em associação às imagens que o manchetista do jornal selecionou. Afinal, a leitura multissemiótica aqui nos leva a uma acepção diferente do que teria a palavra bopecida destituída de um contexto, e toda essa rica discussão se faz importante em sala de aula. Retomando o que já falamos aqui sobre a BNCC, a língua 
é viva e, ao tratá-la a partir de textos atuais, podemos desconstruir a imagem do estudo gramatical como algo estanque, afastado do cotidiano de nossos alunos.

Quanto à iconicidade isotópica, esta dará o sentido superficial do texto com o uso de palavras e expressões para sustentar um temática em questão. A iconicidade isotópica, para Simões (2009, p. 72), é aquela que funciona como uma trilha temática para a formação de sentido, agindo como um recorte temático. É, portanto, uma propriedade de um enunciado a ser substituído por um equivalente no plano do conteúdo, mesmo que diferentes no plano da expressão.

Como exemplo de leitura isotópica, gostaríamos de indicar aqui o artigo "A iconicidade em Clarice Lispector: uma clandestina felicidade", das queridas colegas Carmem Pimentel e Fátima Fabrício (2007), devido ao detalhamento com que as autoras trataram o tema e sua demonstração. No trabalho, as autoras demonstraram inter-relações semiótico-semânticas e estilísticas no emprego de itens lexicais ou mesmo fraseológicos, os quais possibilitam uma diversidade de leituras possíveis no conto clariceano Felicidade Clandestina.

Apenas para elucidação, transcreveremos abaixo uma parte do conto, no qual as autoras mostram algumas 
isotopias (ou trilhas temáticas), na intenção de mostrar como "uma análise literária através de signos abre um leque de interpretações possíveis, permitindo a validação e o aprimoramento da leitura pelo leitor" (PIMENTEL; FABRíclO, 2007, p. 8) . Com isso, as pesquisadoras apontam novos trilhares em busca de aperfeiçoamento de estratégias que contribuam para a formação de leitores e produtores textuais mais competentes, à luz da TIV.

\section{Texto 1 - Análise de gênero conto}

Felicidade Clandestina $(*)$

Ela era gorda, baixa, sardenta e de cabelos excessivamente crespos, meio arruivados. Tinha um busto enorme, enquanto nós todas ainda éramos achatadas. Como se não bastasse, enchia os dois bolsos da blusa, por cima do busto, com balas. Mas possuía o que qualquer criança devoradora de histórias gostaria de ter: um pai dono de livraria.

Pouco aproveitava. E nós menos ainda: até para aniversário, em vez de pelo menos um livrinho barato, ela nos entregava em mãos um cartão-postal da loja do pai. Ainda por cima era de paisagem do Recife mesmo, onde morávamos, com suas pontes mais do que vistas. Atrás escrevia com letra bordadíssima palavras como "data natalícia" e "saudade".

Mas que talento tinha para a crueldade. Ela toda era pura vingança, chupando balas com barulho. Como essa menina devia nos 
odiar, nós que éramos imperdoavelmente bonitinhas, esguias, altinhas, de cabelos livres. Comigo exerceu com calma ferocidade o seu sadismo. Na minha ânsia de ler, eu nem notava as humilhações a que ela me submetia: continuava a implorar-lhe emprestados os livros que ela não lia.

(LISPECTOR, Clarice. Felicidade Clandestina. Rio de Janeiro: Rocco, 1998)

(*) Todas as marcações no texto são das autoras e obedecem à seguinte legenda:

negrito = isotopia do erótico;

$\underline{\text { sublinhado }}=$ isotopia da religiosidade;

envolvido = nós sêmicos (pontos de encontro das isotopias, ou seja, servem de pista para a leitura das duas isotopias: a do erótico e a da religiosidade).

A título de exemplo, as autoras identificaram no texto algumas isotopias: a do erótico, a da religiosidade, a da inveja. No terceiro parágrafo, transcrito acima, a isotopia da inveja se destaca, visto que observamos palavras e fragmentos como: "talento tinha para a crueldade", "era pura vingança", "devia nos odiar, nós que éramos imperdoavelmente bonitinhas, esguias, altinhas, de cabelos livres", "Comigo exerceu com calma ferocidade o seu sadismo." Todo esse levantamento semântico é significativo nas aulas de Língua Portuguesa, pois, além de ativar a ampliação do 
conhecimento lexical do aluno, ainda ajuda a desconstruir a ideia da estanqueidade da interpretação textual. Um mesmo texto poderá ser lido de várias maneiras, de acordo com o recorte de seu leitor, o que evoca semioses ilimitadas dentro daquilo que já definimos aqui como interpretante. Por conseguinte, fica claro que usar a Semiótica como recorte epistemológico mais uma vez se faz necessário, na medida em que corrobora a orientação da BNCC de uma perspectiva enunciativo-discursiva.

A alta ou baixa iconicidade é analisada por meio da captação das isotopias, isto é, trilhas de leitura. Se há facilidade na produção de inferências e deduções pelo leitor, o texto apresenta alta iconicidade. O exemplo do texto literário clariceano que acabamos de ler demonstra bem esse conceito: são várias as possibilidades de leitura oferecidas pelo conto, o que corrobora a antiga tese de que a plurissignificação é uma das características que empresta ao texto um caráter artístico e, portanto, acima do comum.

Ou, como bem disseram as autoras:

Os recortes isotópicos (ou temáticos) identificados [no conto Felicidade Clandestina], nos planos mórfico e sintáticosemântico, são de alta iconicidade, pois as isotopias mostraram-se na superfície do texto, ou seja, foram "perceptíveis ao leitor 
a partir da captação da posição discursiva manifestada na seleção lexical, no modelo gramatical [...], na diagramação (ou projeto visual do texto)" [Simões, 2004], facilitando a produção de inferências, deduções e conclusões, uma vez que a linearidade textual apresenta abundantes elementos orientadores. (PIMENTEL; FABRÍCIO, 2007, p. 3 , grifo nosso)

Por outro lado, se forem apresentadas informações erradas, truncadas, confusas, ou se houver dificuldades no entendimento do texto, estaremos diante de um caso de baixa iconicidade textual, conforme veremos na publicação do Jornal Extra no Twitter.

Figura 7 - Discussão sintática motivada por Tweet ${ }^{4}$

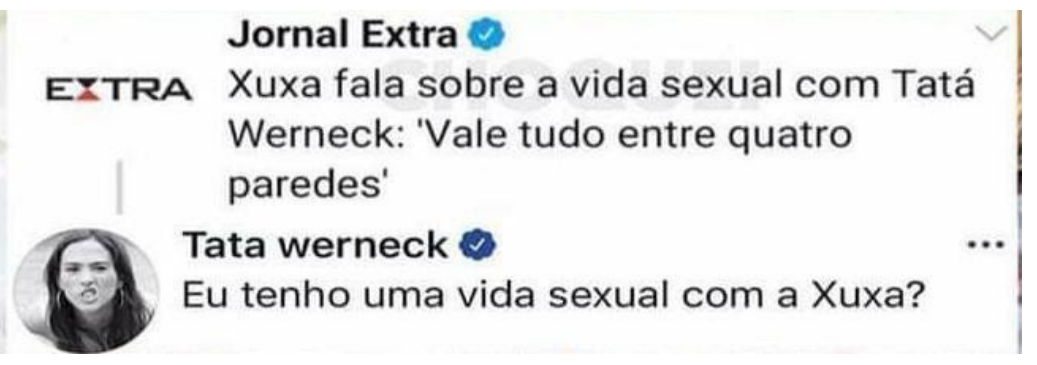

Fonte: https://br.ifunny.co/picture/tata-werneck-xuxa-eu-tenho-uma-vida-sexual-com-aI4HKZQD78/

No Tweet, identificamos um caso de ambiguidade sintática, visto que o sintagma "com Tatá Werneck" pode ser compreendido como um objeto indireto ligado ao verbo falar (fala com Tatá Werneck) - se tomado como sinônimo

4 Acesso em 15 jan. 2021. 
de conversa com Tatá Werceck - ou como um adjunto adnominal de vida sexual (vida com Tatá Werneck), já que o substantivo vida é concreto, não permitindo, portanto, a classificação como complemento nominal (HENRIQUES, 2015, p. 74). Já o termo sobre a vida sexual com Tatá Werneck seria, conseguintemente, adjunto adverbial de assunto, em que tanto sexual como com Tatá Werneck seriam adjuntos adnominais do vocábulo vida.

O problema da construção frasal poderia ser resovido com a antecipação do termo na frase, como em Xuxa fala com Tatá Werneck sobre a vida sexual: "vale tudo entre quatro paredes". No entanto, muito mais do que um exercício metalinguístico de classificação dos termos da oração, o exemplo serviria para algumas discussões de caráter discursivo sobre o uso da língua portuguesa e suas variedades. Assim, algumas questões poderiam ser postuladas: o que é norma culta? Para que serve? O que são variantes? Por que não esperamos de um meio de comunicação uma postagem com esse problema sintático? A ambiguidade da postagem comprometeu a compreensão do enunciado? Por mais que a comediante tenha aproveitado o episódio com bom humor e senso de oportunidade, este é um tipo de exemplo vivo de questões linguísticas que nos 
cercam cotidianamente, sendo, então, papel do professor de língua materna levantar tais questões, até para estimular a criticidade e a autonomia dos educandos, como postulam os documentos oficiais.

Ainda a respeito do exemplo acima, falaremos sobre $a$ eleição de signos orientadores ou desorientadores, conceito, segundo o qual, se verifica a presença ou ausência de signos para guiar o leitor pelo texto. Quando coerente, o texto ativa o mecanismo cognitivo do leitor, fazendo com que aquela leitura tenha sentido. Porém, caso o autor deseje persuadir o leitor e convencê-lo de seus argumentos de forma incoerente, cometendo equívocos ou ambiguidade, ocorrem os signos desorientadores. No comentário da apresentadora Tatá Werneck, a desorientação é algo bastante aparente, pois a própria comediante, a qual também era citada na postagem, mostra sarcasticamente que ficou "confusa" com a natureza da publicação.

\section{CONCLUSÕES PARCIAIS}

Como é possível notar, o assunto é extenso, e vários outros exemplos, de diversos gêneros, poderiam ter sido mencionados, mas o fulcral é que o professor perceba que a mídia ou a literatura, a bem dizer, são fontes constantes de materiais de aula, mesmo que muitos colegas reclamem do 
engessamento a que estão presos em virtude de se sentirem extremamente cobrados para que usem cronogramas impostos por livros didáticos ou outros materiais de ensino. Ainda que reconheçamos a verdade dessas reclamações, não podemos nos esquecer de que exemplos vivos podem ser discutidos com as turmas cotidianamente, seja porque o uso de aparelhos móveis/Smartphones em sala pelos educandos é viável, seja porque boa parte dos materiais didáticos têm sido atualizados bianualmente, o que tem tornado muitas publicações bem ricas de exemplos, inclusive sob o ponto de vista visual.

O grande ponto que subjaz a nossa discussão é que fica evidente o quanto a presença da semiotica é imprescindível no cenário didático-pedagógico. Se o próprio material usado como referência em âmbito nacional se vale do termo e assevera a necessidade de se realizar esse tipo de análise, é no mínimo anacrônico que cursos de formação de professores não o ofereçam em suas matrizes curriculares - ou o façam de forma tacanha, obtusa, passadista, remontando a uma época em que se pensava que interpretação de texto seria assunto adivinhatório, canhestro ou estranho às aulas de Língua Portuguesa.

Com isso, não era intenção aqui oferecer detalhados planos de aula, mas mostrar como a Semiótica pode ser 
farta e ricamente usada no nosso cotidiano pedagógico. Mormente quando se trata da TIV, vemos que ela é plenamente aplicável a qualquer tipo de leitura e discussão, contribuindo com o perfil de alunos que desejamos formar: crítico, participativo, autoral. E, retomando Paulo Freire, com quem abrimos nosso artigo,

na formação permanente dos professores, o momento fundamental é o da reflexão crítica sobre a prática. É pensando criticamente a prática de ou de ontem que se pode melhorar a próxima prática. O próprio discurso teórico, necessário à reflexão crítica, tem de ser de tal modo concreto que quase se confunda com a prática. O seu "distanciamento" epistemológico da prática enquanto objeto de sua análise, deve dela "aproximá -lo" ao máximo. Quanto melhor faça esta operação tanto mais inteligência ganha da prática em análise e maior comunicabilidade exerce em torno da superação da ingenuidade pela rigorosidade. Por outro lado, quanto mais me assumo como estou sendo e percebo a ou as razões de ser de porque estou sendo assim, mais me torno capaz de mudar, de promover-me, no caso, do estado de curiosidade ingênua para o de curiosidade epistemológica. Não é possível a assunção que o sujeito faz de si numa certa forma de estar sendo sem a disponibilidade para mudar. Para mudar e de cujo processo se faz necessariamente sujeito também. (FREIRE, 1996, p. 21) 
Enfim, nas palavras do grande pedagogo nordestino, "ninguém se educa sozinho; os homens se educam em comunhão". Assim, que essa publicação tenha servido não só para homenagear Darcilia Simões, em sua incansável defesa de um ensino de língua de qualidade desde as séries iniciais, até os bancos universitários de graduação, mestrado e doutorado, mas, sobretudo, para fazer despertar em muitos leitores a curiosidade de conhecer mais sobre o tema e, $a$ posteriori, a divulgação deste aporte teórico para muitos outros colegas que possam por ventura bem usá-lo em suas salas de aula.

Que sigamos nos educando em comunhão, comungando dos melhores frutos darcilianos para uma escola de qualidade para as novas gerações.

\section{REFERÊNCIAS}

BAKHTIN, Mikhail. Estética da criação verbal. São Paulo: Martins Fontes, 2003.

BRASIL. Ministério da Educação. Parâmetros Curriculares Nacionais: terceiro e quarto ciclos: Língua Portuguesa. Brasília: MECSEF, 1998.

BRASIL. Ministério da Educação. Base Nacional Comum Curricular. Brasília, 2018.

FREIRE, Paulo. Pedagogia da Autonomia - saberes necessários à prática educativa. 36. ed. São Paulo: Paz e Terra. Coleção Saberes, 1996.

HENRIQUES, Claudio Cezar. Sintaxe: estudos descritivos da frase para o texto. Rio de Janeiro: EPU, 2015. 
$\mathrm{KOCH}$, Ingedore; ELIAS, Vanda Maria. Escrever e argumentar. São Paulo: Contexto, 2018.

MALFACINI, Ana Cristina dos Santos. A importância da semiótica como aporte teório-metodológico nos cursos de Design. In: SIMÕES, Darcilia; FREITAS, Maria Noemi; POLTRONIERI, Ana Lúcia. Linguagens, códigos e tecnologias - estudos e aplicações. Rio de Janeiro: Dialogarts, 2012.

MALFACINI, Ana Cristina dos Santos. Semiótica e ensino da produção textual: diálogos possíveis. In: SIMÕES, Darcilia (Org.). Mídia e comunicação: o verbal e o não verbal em ação. Rio de Janeiro: Dialogarts, 2016.

MALFACINI, Ana Cristina dos Santos; SIMÕES, Darcilia. Pela Teoria da Iconicidade Verbal no ensino da leitura. Disponível em: http://www. filologia.org.br/xiv_cnlf/tomo_4/3155-3166.pdf. Acesso em 24 jan. 2021. MARCUSCHI, Luiz Antônio. Gêneros textuais: definição e funcionalidade. In: DIONISIO, Angela Paiva; MACHADO, Anna Rachel; BEZERRA, Maria Auxiliadora (Orgs.). Gêneros textuais e ensino. Rio de Janeiro: Lucerna, 2002. MARCUSCHI, Luiz Antônio. Produção textual, análise de gêneros e compreensão. São Paulo: Parábola, 2009.

NÖTH, Winfried. Panorama da Semiótica: de Platão a Peirce. São Paulo: Annablume, 1995.

PEIRCE, Charles Sanders. Semiótica. São Paulo: Perspectiva, 2000.

PIMENTEL, Carmen; FABRÍCIO, Fátima. A iconicidade em Clarice Lispector: uma clandestina felicidade. Anais Fórum de Estudos Linguísticos (FELIN), v. 9, 2007.

ROJO, Roxane. Pedagogia doa multiletramentos: diversidade cultural e de linguagens na escola. In: ROJO, Roxane; MOURA, Eduardo. Multiletramentos na escola. São Paulo: Parábola editorial, 2012.

SANTAELLA, Lucia. O que é semiótica. São Paulo: Brasiliense, 2006.

SIMÕES, Darcilia Marindir Pinto. Semiótica, leitura e produção de textos: Alternativas metodológicas. Caderno Seminal Digital, Ano 11, vol. 1, n. 2, p. $125-141$, jul./dez. 
SIMÕES, Darcilia Marindir Pinto. A formação docente em Letras à luz dos parâmetros curriculares nacionais. In: AZEREDO, José Carlos de (Org.). Língua portuguesa em debate: conhecimento e ensino. Petrópolis: Vozes, 2001, p. 112-117.

SIMÕES, Darcilia Marindir Pinto. Iconicidade verbal: Teoria e prática. Rio de Janeiro: Dialogarts publicações, 2009. Disponível em: http://www. dialogarts.uerj.br/admin/arquivos_tfc_lingua/iconicidadeverbal.pdf. Acesso em 20 jan. 2021.

Ana Cristina dos Santos Malfacini é professora adjunta de Língua Portuguesa e Filologia da Universidade do Estado do Rio de Janeiro (UERJ) desde 2015. É mestra em Letras (Linguística e Língua Portuguesa) pela Pontifícia Universidade Católica do Rio de Janeiro - PUC-Rio (2000) e é doutora pelo Instituto de Letras - UERJ (2013). Atualmente, além de lecionar na Educação Básica, é também professora responsável do Centro Universitário de Volta Redonda, onde atua ministrando aulas de Comunicação e Expressão, Português Aplicado e Semiótica Aplicada ao Design. Tem experiência na área de Linguística, com ênfase em Semiótica e Análise e Produção Textual. Sua tese de doutoramento aborda o ensino da produção de textos, abrangendo desde um recorte histórico até uma análise crítica de materiais didáticos usados no ensino hoje. Como fontes teóricas de sua pesquisa, encontram-se autores como Bakhtin, Santaella e Simões. 